\title{
Surface Soil Moisture Retrieval Using Optical/Thermal Infrared Remote Sensing Data
}

\author{
Yawei Wang ${ }^{\circledR}$, Jian Peng, Member, IEEE, Xiaoning Song, Member, IEEE, Pei Leng, \\ Ralf Ludwig, and Alexander Loew, Member, IEEE
}

\begin{abstract}
Surface soil moisture (SSM) plays significant roles in various scientific fields, including agriculture, hydrology, meteorology, and ecology. However, the spatial resolutions of microwave SSM products are too coarse for regional applications. Most current optical/thermal infrared SSM retrieval models cannot directly estimate the quantitative volumetric soil water content without establishing empirical relationships between ground-based SSM measurements and satellite-derived proxies of SSM. Therefore, in this paper, SSM is estimated directly from 5-km-resolution Chinese Geostationary Meteorological Satellite FY-2E data based on an elliptical-new SSM retrieval model developed from the synergistic use of diurnal cycles of land surface temperature (LST) and net surface shortwave radiation (NSSR). The elliptical-original model was constructed for bare soil and did not consider the impacts of different fractional vegetation cover (FVC) conditions. To optimize the ellipticaloriginal model for regional-scale SSM estimates, it is improved in this paper by considering the influence of FVC, which is based on a dimidiate pixel model and a Moderate Resolution Imaging Spectroradiometer normalized difference vegetation index product. A preliminary validation of the model is conducted based on ground measurements from the counties of Maqu, Luqu, and Ruoergai in the source area of the Yellow River. A correlation coefficient (R) of 0.620 , a root-mean-square error (RMSE) of $0.146 \mathrm{~m}^{3} / \mathrm{m}^{3}$, and a bias of $0.038 \mathrm{~m}^{3} / \mathrm{m}^{3}$ were obtained when comparing the in situ measurements with the FY-2E-derived SSM using the elliptical-original model. In contrast, the FY-2Ederived SSM using the elliptical-new model exhibited greater consistency with the ground measurements, as evidenced by an $R$ of 0.845 , an RMSE of $0.064 \mathrm{~m}^{3} / \mathrm{m}^{3}$, and a bias of $0.017 \mathrm{~m}^{3} / \mathrm{m}^{3}$. To provide accurate SSM estimates, high-accuracy FVC, LST, and NSSR data are required. To complement the point-scale
\end{abstract}

Manuscript received August 23, 2017; revised December 22, 2017 and March 12, 2018; accepted March 14, 2018. This work was supported in part by the National Natural Science Foundation of China under Grant 41601397 and in part by the Scientific Exploitation of Operational Missions Program of the European Space Agency through the project "Exploitation of S-1 for Surface Soil Moisture Retrieval at High Resolution" under Contract 4000118762/16/INB (https://exploit-s-1.ba.issia.cnr.it). The work of Y. Wang was supported by China Scholarship Council. (Corresponding author: Yawei Wang.)

Y. Wang, R. Ludwig, and A. Loew is with the Geography Department, Ludwig Maximilian University of Munich, 80337 Munich, Germany (e-mail: yawei.wang1@gmail.com).

J. Peng is with the School of Geography and the Environment, University of Oxford, Oxford OX1 3QY, U.K., with the Geography Department, Ludwig Maximilian University of Munich, 80337 Munich, Germany, and also with the Max Planck Institute for Meteorology, 20146 Hamburg, Germany.

$\mathrm{X}$. Song is with the College of Resources and Environment, University of Chinese Academy of Sciences, Beijing 100049, China.

P. Leng is with the Key Laboratory of Agri-Informatics, Ministry of Agriculture/Institute of Agricultural Resources and Regional Planning, Chinese Academy of Agricultural Sciences, Beijing 100081, China.

Color versions of one or more of the figures in this paper are available online at http://ieeexplore.ieee.org.

Digital Object Identifier 10.1109/TGRS.2018.2817370 validation conducted here, cross-comparisons with other existing SSM products will be conducted in the future studies.

Index Terms-Ellipse model, land surface temperature (LST), net surface shortwave radiation (NSSR), optical/thermal infrared data, surface soil moisture (SSM).

\section{INTRODUCTION}

$\mathbf{S}$ URFACE soil moisture (SSM), which is represented by water that is retained in the top few centimeters (approximately 0 to $5 \mathrm{~cm}$ ) of the soil, represents an important connection between the land surface and the atmosphere [1]-[6]. Real-time, accurate SSM monitoring plays critical roles in guiding agricultural irrigation and production forecasts for agricultural applications [7]. As a significant component of the hydrological cycle, SSM effectively regulates the partitioning of rainfall into infiltration and runoff. Furthermore, soil moisture was listed as an essential climate variable by the World Meteorological Organization in 2010 due to its impacts on climate change over a temporal range of hours to years. In addition, SSM is closely associated with various fundamental areas of research and many scientific disciplines [8]-[12].

Both regional- and global-scale quantitative estimates of SSM are essential. However, due to the combined effects of weather and surface conditions, SSM displays broad heterogeneity at both temporal and spatial scales [13], [14]. Therefore, it is particularly difficult to acquire quantitative estimates of SSM at the regional scale. Numerous investigations have focused on obtaining regional-scale SSM estimates [15]-[20]. Although microwave remote sensing of SSM has various deficiencies including a lack of soil roughness information and problems arising from sun-glint contamination at the L-band, microwave band has all-day observation capability [21]. Some SSM products have been produced based on the Advanced Microwave Scanning Radiometer-Earth Observing System instrument, the Soil Moisture Ocean Salinity mission, the climate change initiative, and the Soil Moisture Active Passive [22]-[28]. However, the spatial resolutions of microwave SSM products are overly coarse (approximately $25-50 \mathrm{~km}$ ) for regional applications. Optical/thermal infrared data have the advantage of a high spatial resolution, and thus, the estimation of SSM from optical/thermal infrared data has been attempted in several studies [29]-[31]. However, most existing methods cannot quantitatively estimate the volumetric soil water content directly without establishing empirical 
relationships between SSM measurements and satellite-derived proxies of SSM.

The increasing number of geostationary satellites is facilitating the development of more practical SSM retrieval methods with higher spatial and temporal resolutions [31]-[36]. Geostationary satellites have a higher frequency of observations than do polar orbiting satellites and can produce 48 to 96 images per day with a fixed observation angle for a given pixel, substantially enriching our understanding of terrestrial water and energy budgets. A novel SSM retrieval model was proposed by Leng et al. [32], [33] to directly estimate SSM without ground soil moisture data for calibration. This model is based on the synergistic use of diurnal cycles of land surface temperature (LST) and net surface shortwave radiation (NSSR) data obtained from geostationary satellite data. This innovative ellipse model exhibits some advantages over other methods that utilize optical/thermal infrared data. First, the ellipse model is capable of directly estimating SSM without establishing empirical relationships between fieldscale soil moisture measurements and remotely sensed parameters. Field-scale soil moisture measurements are essential for many SSM retrieval models but are difficult to obtain. Consequently, the ellipse model is less labor intensive and more convenient. Second, the ellipse model can estimate SSM via a great number of approaches than can other methods. Polar orbiting satellites can only observe one target once every $12 \mathrm{~h}$. If it is cloudy during the satellite pass, the retrieval method will provide no information. However, the ellipse model requires only five of 48/96 images, offering a greater probability of estimating the SSM. Following the approaches of previous investigations, this paper aims to analyze the effects of fractional vegetation cover (FVC) and to optimize the elliptical-original model over different vegetation cover types. A preliminary validation of the model is conducted using ground measurements for the counties of Maqu, Luqu, and Ruoergai.

\section{STUdy AREA AND DATA}

\section{A. Description of the Study Area}

The study area, which includes the counties of Maqu, Luqu, and Ruoergai $\left(33.05^{\circ} \mathrm{N}-34.81^{\circ} \mathrm{N}, 100.76^{\circ} \mathrm{E}-103.61^{\circ} \mathrm{E}\right)$, is located to the east of the source area of the Yellow River (SAYR), the catchment of which lies above the Tangnag Hydrological Station in the Northeastern Qinghai-Tibet Plateau [37]. The area encompasses a large river valley and surrounding hills, wetlands, grassland, and bare areas. The climate is wet and cold with dry winters and rainy summers due to the monsoon season. The mass and energy fluxes between the land surface and the atmosphere in the QinghaiTibet Plateau have substantial effects on regional and global climates. Thus, studying the SSM over the study area in the Qinghai-Tibet Plateau is of great significance.

\section{B. FY-2E Data}

The FY-2 series of satellites, which were launched by China beginning in 2001, consists of five geostationary meteorological satellites FY-2C/2D/2E/2F/2G. The FY-2E satellite
TABLE I

Main TeChnical Specifications of The Radiometer

\begin{tabular}{cccc}
\hline Channel & $\begin{array}{c}\text { Spectral range } \\
(\mu \mathrm{m})\end{array}$ & $\begin{array}{c}\text { Spatial } \\
\text { resolution }(\mathrm{km})\end{array}$ & $\mathrm{NE} \Delta \mathrm{T} 300 \mathrm{~K}$ \\
\hline VIS & $0.510-0.905$ & 1.25 & - \\
IR1 & $10.29-11.45$ & 5 & $0.19 \mathrm{~K}$ \\
IR2 & $11.59-12.79$ & 5 & $0.26 \mathrm{~K}$ \\
IR3 & $3.59-4.09$ & 5 & $0.30 \mathrm{~K}$ \\
IR4 & $6.32-7.55$ & 5 & $0.19 \mathrm{~K}$ \\
\hline
\end{tabular}

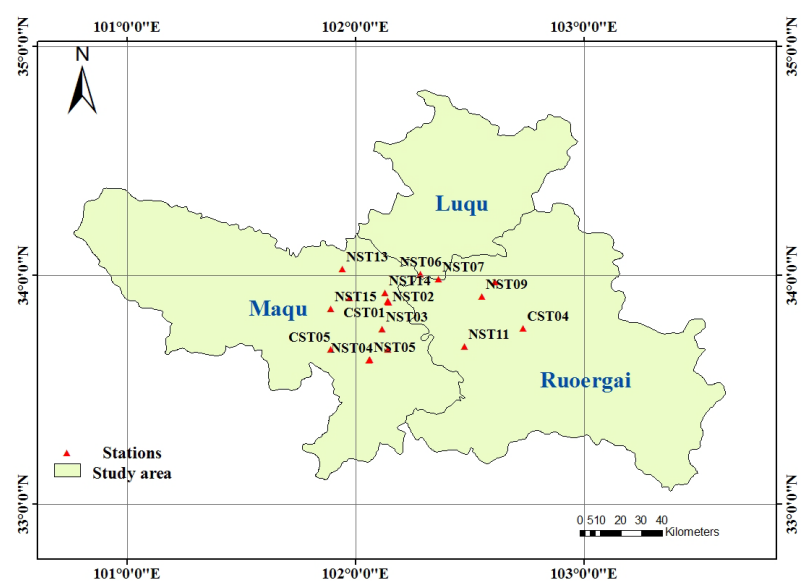

Fig. 1. Map of the study area, which includes the counties of Maqu, Luqu, and Ruoergai.

was launched at the end of 2008 to replace FY-2C. The optical imaging radiometer onboard the FY-2E satellite is a stretched-visible and infrared spin-scan radiometer (S-VISSR) that includes one visible channel and four infrared thermal channels (Table I) [38]. FY-2E can obtain one full disc image per hour or every $30 \mathrm{~min}$ that covers the earth's surface over latitudes from $60^{\circ} \mathrm{N}$ to $60^{\circ} \mathrm{S}$ and longitudes from $45^{\circ} \mathrm{E}$ to $165^{\circ} \mathrm{E}$ during the flooding season. FY-2E data are obtained from the National Satellite Meteorological Center (http://www.nsmc.cma.gov.cn/NSMC/Home/Index.html).

\section{Ground Soil Temperature Measurements}

The soil moisture monitoring network used in this paper was installed by the Cold and Arid Regions Environmental and Engineering Research Institute and the Faculty of GeoInformation Science and Earth Observation of the University of Twente, Enschede, The Netherlands; the stations are shown in Fig. 1. Table II displays information on the soil moisture monitoring stations, which was derived from the coordinated Asia-European long-term observing system of Qinghai-Tibet Plateau hydrometeorological processes and the Asian-monsoon system with ground satellite image data and numerical simulations report "continuous in situ soil moisture measurements at Maqu site" by L. Dente, Z. Vekerdy, $\mathrm{Z}$. Su, and J. Wen. The ground measurements represent the soil moisture at a depth of approximately $5 \mathrm{~cm}$, which is most closely related to the SSM estimates retrieved from satellite data in this paper. 
TABLE II

NETWORK STATION INFORMATION

\begin{tabular}{|c|c|c|c|c|c|c|c|c|c|}
\hline Station ID & Latitude/Longitude & $\begin{array}{l}\text { Elevation } \\
(\mathrm{m})\end{array}$ & Topography & $\begin{array}{l}\text { Land } \\
\text { cover }\end{array}$ & Station ID & $\begin{array}{c}\text { Latitude/Longit } \\
\text { ude }\end{array}$ & Elevation(m) & $\begin{array}{l}\text { Topograp } \\
\text { hy }\end{array}$ & $\begin{array}{l}\text { Land } \\
\text { cover }\end{array}$ \\
\hline CST_01 & $\begin{array}{c}33^{\circ} 53^{\prime} 14.16^{\prime \prime} \\
102^{\circ} 08^{\prime} 25.62^{\prime \prime}\end{array}$ & 3431 & River valley & Grass & NST_06 & $\begin{array}{c}34^{\circ} 00^{\prime} 29.70^{\prime \prime} \\
102^{\circ} 16^{\prime} 53.58^{\prime \prime}\end{array}$ & 3428 & $\begin{array}{l}\text { River } \\
\text { valley }\end{array}$ & Grass \\
\hline CST_02 & $\begin{array}{c}33^{\circ} 40^{\prime} 42.60^{\prime \prime} \\
102^{\circ} 08^{\prime} 18.66^{\prime \prime}\end{array}$ & 3449 & River valley & Grass & NST_07 & $\begin{array}{c}33^{\circ} 59^{\prime} 13.74^{\prime \prime} \\
102^{\circ} 21^{\prime} 37.20^{\prime \prime}\end{array}$ & 3430 & $\begin{array}{l}\text { River } \\
\text { valley }\end{array}$ & Grass \\
\hline CST_03 & $\begin{array}{c}33^{\circ} 54^{\prime} 17.82^{\prime \prime} \\
101^{\circ} 58^{\prime} 15.66^{\prime \prime}\end{array}$ & 3507 & Hill valley & Grass & NST_08 & $\begin{array}{c}33^{\circ} 58^{\prime} 19.44^{\prime \prime} \\
102^{\circ} 36^{\prime} 31.08^{\prime \prime}\end{array}$ & 3473 & valley & Grass \\
\hline CST_04 & $\begin{array}{c}33^{\circ} 46^{\prime} 12.84^{\prime \prime} \\
101^{\circ} 43^{\prime} 52.98^{\prime \prime}\end{array}$ & 3504 & Hill valley & Grass & NST_09 & $\begin{array}{c}33^{\circ} 54^{\prime} 38.64^{\prime \prime} \\
102^{\circ} 33^{\prime} 00.78^{\prime \prime}\end{array}$ & 3434 & $\begin{array}{l}\text { River } \\
\text { valley }\end{array}$ & Grass \\
\hline CST_05 & $\begin{array}{c}33^{\circ} 40^{\prime} 46.50^{\prime \prime} \\
101^{\circ} 53^{\prime} 21.78^{\prime \prime}\end{array}$ & 3542 & Hill valley & Grass & NST_10 & $\begin{array}{c}33^{\circ} 51^{\prime} 07.74^{\prime \prime} \\
102^{\circ} 34^{\prime} 25.44^{\prime \prime}\end{array}$ & 3512 & Hill slope & Grass \\
\hline NST_01 & $\begin{array}{c}33^{\circ} 53^{\prime} 22.68^{\prime \prime} \\
102^{\circ} 08^{\prime} 27.48^{\prime \prime}\end{array}$ & 3431 & River valley & Grass & NST_11 & $\begin{array}{c}33^{\circ} 41^{\prime} 33.18^{\prime \prime} \\
102^{\circ} 28^{\prime} 36.12^{\prime \prime}\end{array}$ & 3442 & $\begin{array}{l}\text { River } \\
\text { valley }\end{array}$ & $\begin{array}{l}\text { Wetland } \\
\text { grass }\end{array}$ \\
\hline NST_02 & $\begin{array}{c}33^{\circ} 53^{\prime} 04.74^{\prime \prime} \\
102^{\circ} 08^{\prime} 32.28^{\prime \prime}\end{array}$ & 3434 & River valley & Grass & NST_12 & $\begin{array}{c}33^{\circ} 37^{\prime} 16.02^{\prime \prime} \\
102^{\circ} 28^{\prime} 00.36^{\prime \prime}\end{array}$ & 3441 & $\begin{array}{l}\text { River } \\
\text { valley }\end{array}$ & Grass \\
\hline NST_03 & $\begin{array}{c}33^{\circ} 46^{\prime} 00.54^{\prime \prime} \\
102^{\circ} 08^{\prime} 50.52^{\prime \prime}\end{array}$ & 3513 & Hill slope & Grass & NST_13 & $\begin{array}{c}34^{\circ} 01^{\prime} 53.70^{\prime \prime} \\
101^{\circ} 56^{\prime} 31.44^{\prime \prime}\end{array}$ & 3519 & valley & Grass \\
\hline NST_04 & $\begin{array}{c}33^{\circ} 37^{\prime} 52.14^{\prime \prime} \\
102^{\circ} 03^{\prime} 25.56^{\prime \prime}\end{array}$ & 3448 & River valley & $\begin{array}{l}\text { Wetlan } \\
\text { d grass }\end{array}$ & NST_14 & $\begin{array}{c}33^{\circ} 55^{\prime} 35.64^{\prime \prime} \\
102^{\circ} 07^{\prime} 42.78^{\prime \prime}\end{array}$ & 3432 & $\begin{array}{l}\text { River } \\
\text { valley }\end{array}$ & Grass \\
\hline NST_05 & $\begin{array}{c}33^{\circ} 38^{\prime} 05.10^{\prime \prime} \\
102^{\circ} 03^{\prime} 34.68^{\prime \prime}\end{array}$ & 3476 & Hill slope & Grass & NST_15 & $\begin{array}{c}33^{\circ} 51^{\prime} 26.10^{\prime \prime} \\
101^{\circ} 53^{\prime} 28.08^{\prime \prime}\end{array}$ & 3752 & Hill slope & Grass \\
\hline
\end{tabular}

\section{Simulated Data}

Simulated data from the common land model (CoLM) are used to improve the elliptical-original SSM retrieval model [39]. Various studies show that the CoLM provides reasonable simulations of the land surface state in Northwestern China and the Tibetan Plateau, including at Maqu station, which is located in the current study area [40]. The CoLM can adequately represent basic features of the land surface energy balance at daily time scales in China [41].

The CoLM primarily represents physical, hydrological, and biological processes and exhibits high accuracy in the simulation of multiple parameters, including snow cover, soil moisture, sensible heat flux, and latent heat flux. Atmospheric forcing data that are employed for driving the CoLM primarily encompass the downward solar radiation, downward longwave radiation, wind speed, wind direction, precipitation, air temperature at a reference height, atmospheric pressure at the surface, and relative humidity at a reference height.

\section{Methodology}

\section{A. Elliptical-Original SSM Retrieval Model}

The diurnal LST cycle can be described as a sine or cosine function. The daytime part of the diurnal temperature cycle model can be expressed as follows [42]:

$$
T_{\text {day }}(t)=T_{0}+T_{a} \cos \left[\beta\left(t-t_{m}\right)\right]
$$

where $T_{\text {day }}(t)$ is the LST $(K)$ at time $t$ (hours), $T_{0}$ is the residual temperature at sunrise, $T_{a}$ is the temperature amplitude, $\beta$ is the width of the half-period of the cosine term, and $t_{m}$ is the time at which the temperature reaches its maximum.

A similar cosine function can be used to express the diurnal NSSR cycle

$$
S_{\text {day }}(t)=S_{0}+S_{a} \cos \left[\alpha\left(t-t_{r}\right)\right]
$$

where $S_{\text {day }}(t)$ is the NSSR $\left(\mathrm{W} / \mathrm{m}^{2}\right)$ at time $t$ (hours), $S_{0}$ is the residual NSSR at sunrise, $S_{a}$ is the NSSR amplitude, $\alpha$ is the width of the half-period of the cosine term, and $t_{r}$ is the time (hours) of the maximum NSSR.

To facilitate investigating the relationship between the diurnal cycles of LST and NSSR and simplify the expression, LST and NSSR can be made dimensionless as follows:

$$
\begin{aligned}
& x=\frac{T_{\text {day }}(t)-s}{r-s}=p_{1} \cos \left[\beta\left(t-t_{m}\right)\right]+q_{1} \\
& y=\frac{S_{\text {day }}(t)-j}{k-j}=p_{2} \cos \left[\alpha\left(t-t_{r}\right)\right]+q_{2}
\end{aligned}
$$

where $x$ and $y$ are the dimensionless LST and NSSR, respectively, $r$ and $s$ are set as 325 and $275 \mathrm{~K}$, respectively, and $k$ and $j$ are set as 1200 and $0 \mathrm{~W} / \mathrm{m}^{2}$, respectively. $p_{1}, q_{1}, p_{2}$, and $q_{2}$ are parameters of the diurnal LST and NSSR cycles.

For a day of clear skies, it is assumed that $\beta$ in (1) is equal to $\alpha$ in (2). The difference between maximum LST time $t_{m}$ and maximum NSSR time $t_{r}$ is calculated as follows:

$$
\Delta t=t_{m}-t_{r} .
$$

An elliptical relationship exists between LST and NSSR during the daytime on fully cloud-free days, which can be expressed as follows [33]:

$$
\begin{array}{r}
p_{2}^{2}\left(x-q_{1}\right)^{2}-2 p_{1} p_{2}[\cos (\beta \cdot \Delta t)]\left(x-q_{1}\right)\left(y-q_{2}\right)+p_{1}^{2}\left(y-q_{2}\right)^{2} \\
=\left[p_{1} p_{2} \sin (\beta \cdot \Delta t)\right]^{2}
\end{array}
$$

For a given atmospheric condition, $p_{1}, q_{1}, p_{2}, q_{2}, \beta$, and $\Delta t$ are constants for a particular soil type and soil moisture content. The ellipse parameters, including the center horizontal coordinate $\left(x_{0}\right)$, the center vertical coordinate $\left(y_{0}\right)$, the semimajor axis $(a)$, the semiminor axis $(b)$, and the rotation angle $(\theta)$, can be calculated as follows:

$$
\left\{\begin{array}{l}
x_{0}=q_{1} \\
y_{0}=q_{2} \\
\theta=\frac{1}{2} \cot ^{-1}\left[\frac{p_{1}^{2}-p_{2}^{2}}{2 p_{1} p_{2} \cos (\beta \cdot \Delta t)}\right] \\
a=p_{1} \sin (\beta \cdot \Delta t) \\
b=p_{2} \sin (\beta \cdot \Delta t) .
\end{array}\right.
$$




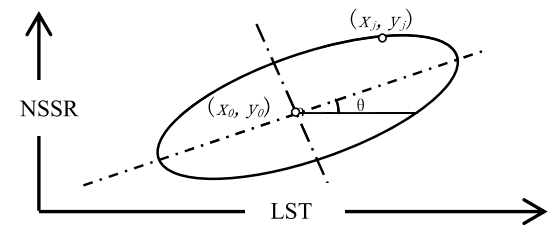

Fig. 2. Diagram of the elliptical relationship between the diurnal cycles of the LST and NSSR. $x_{0}, y_{0}, a$, and $\theta$ represent the horizontal and vertical coordinates of the ellipse center, the semimajor axis, and the rotation angle, respectively. $\left(x_{j}, y_{j}\right)$ represent the LST and NSSR at time $j$ $(j=1,2,3,4,5)$

The elliptical relationship varies with different soil types and soil moisture contents under a given atmospheric condition. Furthermore, there is an elliptical relationship between the diurnal LST and NSSR cycles, as shown in Fig. 2. A stepwise regression method is used to determine the parameters for SSM retrieval. With the simulated data, it is found that the four ellipse parameters $\left(x_{0}, y_{0}, a\right.$, and $\left.\theta\right)$ are the most significant for the estimation of SSM. However, the center horizontal coordinate $x_{0}$ and the rotation angle $\theta$ have a strong linear relationship [38].

Therefore, the newly developed SSM retrieval model can be written as follows [33], [38]:

$$
\mathrm{SSM}=n_{1} \times y_{0}+n_{2} \times a+n_{3} \times \ln \theta+n_{0}
$$

where SSM is the daily-averaged $\mathrm{SSM}\left(\mathrm{m}^{3} / \mathrm{m}^{3}\right), y_{0}, a$, and $\theta$, which, respectively, represent the vertical coordinates of the ellipse center, the semimajor axis and the rotation angle, are the ellipse parameters for the elliptical relationship between the diurnal LST and NSSR cycles, and $n_{i}(i=0,1,2,3)$ is the model coefficients $\left(\mathrm{m}^{3} / \mathrm{m}^{3}\right)$ that can be simulated from the CoLM. It should be noticed that elliptical parameters and model coefficients will change with different days.

\section{B. Determination of LST}

The diurnal cycles of LST and NSSR are prerequisite information for the elliptical SSM retrieval model. As determined in [43] and [44], LST can be expressed as follows based on the split-window algorithm [45]:

$$
\begin{aligned}
T_{s}=a_{0}+\left(a_{1}+a_{2}\right. & \left.\frac{1-\varepsilon}{\varepsilon}+a_{3} \frac{\delta \varepsilon}{\varepsilon^{2}}\right) \frac{T_{\mathrm{IR} 1}+T_{\mathrm{IR} 2}}{2} \\
& +\left(a_{4}+a_{5} \frac{1-\varepsilon}{\varepsilon} a_{6} \frac{\delta \varepsilon}{\varepsilon^{2}}\right) \frac{T_{\mathrm{IR} 1} T_{\mathrm{IR} 2}}{2}
\end{aligned}
$$

where $T_{\mathrm{IR} 1}$ and $T_{\mathrm{IR} 2}$ are the top-of-atmosphere (TOA) brightness temperatures $(K)$ measured in channels IR1 and IR2; $\varepsilon$ is the averaged emissivity from channels IR1 and IR2 of FY-2E which can be estimated from the LSEs in channels 31 and 32 of Moderate Resolution Imaging Spectroradiometer (MODIS) provided by the MODIS LST product MOD11A1; $\delta \varepsilon$ is the emissivity difference between the two thermal infrared channels IR1 and IR2; and $a_{0}-a_{6}$ are unknown coefficients that can be derived from the simulated data through statistical regression methods for each viewing zenith angle and subrange. The University of California Santa Barbara, Santa Barbara, CA, USA, spectral database was used to determine the emissivity relationship between the S-VISSR channels and the MODIS 31 and 32 channels [44].

\section{Determination of NSSR}

NSSR is mainly calculated using downward surface shortwave radiation (DSSR), upward surface shortwave radiation (USSR), and land surface albedo as follows [46], [47]:

$$
\begin{aligned}
S_{n}= & R_{s}^{\downarrow}-R_{s}^{\uparrow}=(1-r) R_{s}^{\downarrow} \\
R_{s}^{\downarrow}= & G \times \cos (\mathrm{SZA}) \times d_{r} \times \tau \\
d_{r}= & 1.00011+0.034221 \cos (\alpha)+0.00128 \sin (\alpha) \\
& +0.000719 \cos (2 \alpha)+0.000077 \sin (2 \alpha) .
\end{aligned}
$$

According to Tang et al.[43] and Li et al.[48], the atmospheric water vapor content (WVC) can be derived from the transmittance ratio of the split-window channels. The relationship between the transmittance ratio and WVC is determined by synthetic regression on the simulated data from MODTRAN with aerosol model (VIS $=23 \mathrm{~km}$, rural model)

$$
\begin{aligned}
\mathrm{WVC} & =C_{1}+C_{2} \times \frac{\tau_{\mathrm{IR} 2}}{\tau_{\mathrm{IR} 1}} \\
\frac{\tau_{\mathrm{IR} 2}}{\tau_{\mathrm{IR} 1}} & =\frac{\varepsilon_{\mathrm{IR} 1}}{\varepsilon_{\mathrm{IR} 2}} \times \frac{\sum_{k=1}^{N}\left(T_{\mathrm{IR} 1, k}-\overline{T_{\mathrm{IR} 1}}\right)\left(T_{\mathrm{IR} 2, k}-\overline{T_{\mathrm{IR} 2}}\right)}{\sum_{k=1}^{N}\left(T_{\mathrm{IR} 1, k}-\overline{T_{\mathrm{IR} 1}}\right)^{2}} \\
C_{1} & =28.104-\frac{14.996}{\cos (\mathrm{VZA})}+\frac{3.211}{\cos ^{2}(\mathrm{VZA})} \\
C_{2} & =-28.056+\frac{14.954}{\cos (\mathrm{VZA})}-\frac{3.206}{\cos ^{2}(\mathrm{VZA})} \\
\alpha & =\frac{2 \pi(\mathrm{DOY}-1)}{365}
\end{aligned}
$$

where $S_{n}$ is the $\operatorname{NSSR}\left(\mathrm{W} / \mathrm{m}^{2}\right) ; R_{S}^{\downarrow}$ and $R_{S}^{\uparrow}$ represent the $\operatorname{DSSR}\left(\mathrm{W} / \mathrm{m}^{2}\right)$ and USSR $\left(\mathrm{W} / \mathrm{m}^{2}\right)$, respectively; $r$ is the land surface albedo; $G$ is the solar constant $\left(1367 \mathrm{~W} / \mathrm{m}^{2}\right)$; SZA is the solar zenith angle; $d_{r}$ is the earth-sun distance factor; $\tau$ is the atmospheric transmissivity; DOY denotes the day of year; WVC is the water vapor content $\left(\mathrm{g} / \mathrm{cm}^{2}\right) ; \tau_{\mathrm{IR} 1}$ and $\tau_{\mathrm{IR} 2}$ are the atmospheric transmittances in channels IR1 and IR2; $\varepsilon_{\text {IR1 }}$ and $\varepsilon_{\text {IR2 }}$ are the emissivities in channels IR1 and IR2; and $\bar{T}_{\text {IR1 }}$ and $\bar{T}_{\text {IR2 }}$ are the TOA mean channel brightness temperatures $(K)$ of the $N$ neighboring pixels in channels IR1 and IR2, respectively.

\section{Elliptical-New SSM Retrieval Model}

1) Improvement With FVC: The elliptical-original model was constructed for bare soil conditions with coefficients that do not reflect conditions with varying FVC. The coefficients for bare soil are used for SSM estimates under conditions where the FVC is less than 0.7. However, the FVC is temporally variable, and thus, using the same set of coefficients to derive the SSM under different vegetation conditions can produce errors. Accordingly, it is necessary to account for FVC 


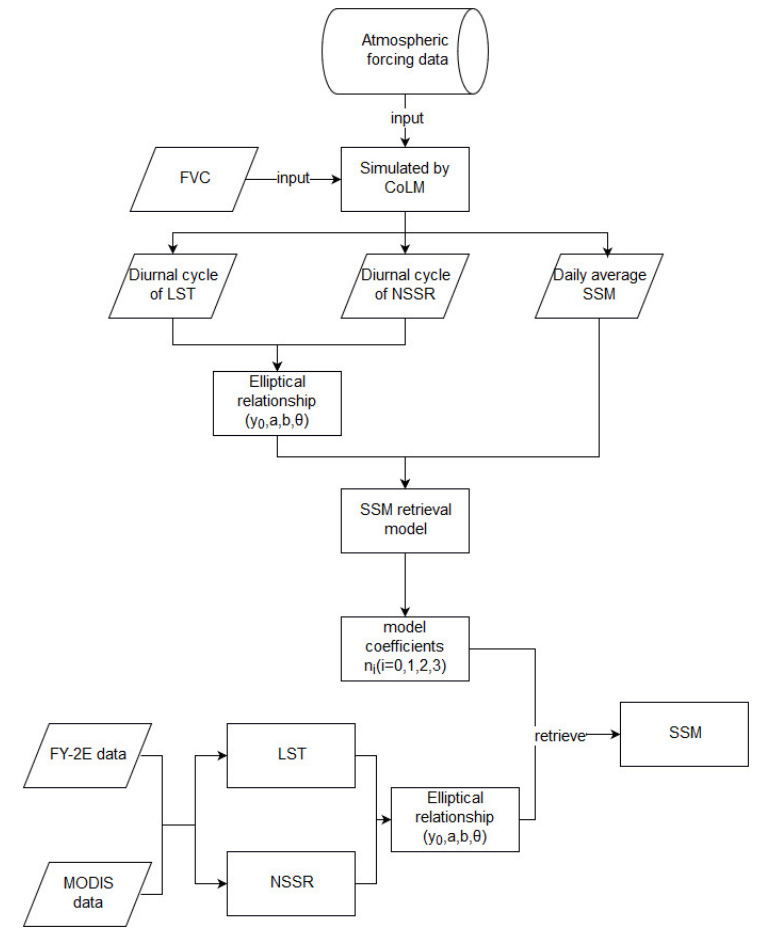

Fig. 3. Flowchart of the development of the daily-averaged SSM retrieval model.

to optimize the elliptical-original model for use at temporal and spatial scales.

The FVC can be derived from a widely used dimidiate pixel model, a linear pixel unmixing model, and a MODIS normalized difference vegetation index (NDVI) product (16-day MOD13Q1) [49], [50]. This derivation assumes that each pixel can be decomposed into a linear combination of bare soil (NDVIsoil) and full vegetation (NDVIveg) as follows:

$$
\mathrm{FVC}=(\text { NDVI }- \text { NDVIsoil) } /(\text { NDVIveg }- \text { NDVIsoil })
$$

where FVC is the fractional vegetation cover, NDVI is the normalized difference vegetation index, NDVIsoil is the NDVI of the bare soil, and NDVIveg is the NDVI of the vegetation. Due to inevitable noise, cumulative probabilities of $0.5 \%$ and $99.5 \%$ are taken for NDVIsoil and NDVIveg, respectively, in this paper.

2) Experimental Procedure: Fig. 3 depicts the process of using the elliptical-new SSM retrieval model with geostationary satellite data in detail. The data for CoLM simulation are similar to those used in [22] and [51]. The initializations of soil textures about the soil texture classification scheme of the Food and Agriculture Organization are computed from Bonan [52]. Besides, the land cover is initialized according to the United States Geological Survey vegetation categories and FVC, which is set at $0-0.7$ for the study area. Atmospheric forcing data are used to drive the CoLM, as mentioned earlier in the reference to the simulated data. As indicated in the flowchart, FVC is input into the CoLM along with atmospheric forcing data to directly produce simulated data, including the diurnal cycle of LST, the diurnal cycle of NSSR, and the daily-averaged SSM, to construct the database. The model

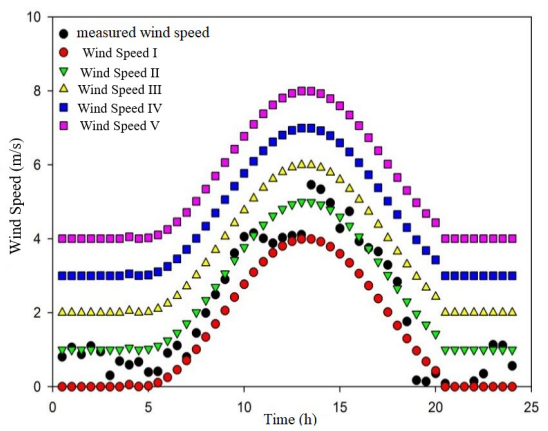

Fig. 4. Measured wind speed and five sets of simulated wind speeds.

TABLE III

VALidation SSM RETRIEVAls With DifFERENT Wind SPEEDS

\begin{tabular}{c|c|c}
\hline Wind Speed & $\mathrm{R}^{2}$ & $\mathrm{RMSE}\left(\mathrm{m}^{3} \mathrm{~m}^{-3}\right)$ \\
\hline I & 0.912 & 0.024 \\
II & 0.919 & 0.022 \\
III & 0.866 & 0.029 \\
IV & 0.726 & 0.044 \\
V & 0.608 & 0.057 \\
\hline
\end{tabular}

coefficients are then calculated from the simulated dailyaveraged SSM and diurnal cycles of LST and NSSR. Similarly, based on the geostationary satellite data, elliptical relationships are built with the ellipse parameters. The SSM can be successfully produced with the model coefficients and ellipse parameters.

\section{Results AND ANALYsis}

\section{A. Effect of Atmospheric Forcing Data on the Elliptical-New SSM Model}

The model coefficients simulated from the CoLM are based on atmospheric forcing data. However, atmospheric forcing varies temporally and spatially. Therefore, atmospheric forcing data will affect SSM retrieval. Wind speed, air temperature, and relative humidity are the atmospheric forcing variables, most likely to affect the accuracy of the elliptical-new SSM retrieval model. In this paper, the model errors from wind speed, air temperature, and relative humidity are analyzed.

1) Effect of Wind Speed on the Elliptical-New SSM Retrieval Model: Wind speed has a strong diurnal cycle, with a peak in the afternoon (2 PM) over most land areas [53], [54]. While controlling other atmospheric forcing variables, diurnal LST, diurnal NSSR, and daily SSM are simulated under different wind speeds based on the CoLM. Taking the atmospheric forcing data on DOY 217 in 2010 as an example, different diurnal wind speeds are set based on measured wind speed, as shown in Fig. 4.

After calculating the model coefficients with different wind speeds, the SSM retrievals are validated with in situ measurements, as shown in Table III. The accuracy of the wind speed data affects SSM retrieval. If the uncertainty of wind speed is less than $1 \mathrm{~m} / \mathrm{s}$, the accuracy of the result might not be significantly affected. As the uncertainty of wind 


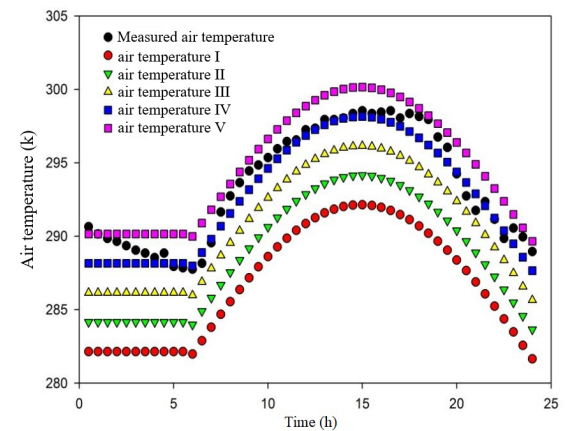

Fig. 5. Measured air temperature and five sets of simulated air temperature.

TABLE IV

VALIDATION SSM RETRIEVALS With DifFERENT AiR TEMPERATURES

\begin{tabular}{c|c|c}
\hline $\begin{array}{c}\text { Air } \\
\text { temperature }\end{array}$ & $\mathrm{R}^{2}$ & $\mathrm{RMSE}\left(\mathrm{m}^{3} / \mathrm{m}^{3}\right)$ \\
\hline I & 0.808 & 0.045 \\
II & 0.804 & 0.043 \\
III & 0.749 & 0.044 \\
IV & 0.842 & 0.031 \\
V & 0.867 & 0.028 \\
\hline
\end{tabular}

speed increases, the SSM retrievals will become increasingly inaccurate, with large uncertainties at wind speed uncertainties in excess of $3 \mathrm{~m} / \mathrm{s}$.

2) Effect of Air Temperature on the Elliptical-New SSM Retrieval Model: Air temperature has a strong diurnal cycle, with a peak in the afternoon over most land areas. Taking the DOY 217 in 2010 as an example, simulated data are produced based on the CoLM with different diurnal air temperatures, as shown in Fig. 5. The SSM retrievals are validated with in situ measurements, as shown in Table IV. As the uncertainty of air temperature increases, the retrievals display larger errors. As the uncertainty of air temperature reaches a threshold, the error of SSM retrieval tends to be stable within $0.02 \mathrm{~m}^{3} / \mathrm{m}^{3}$. Therefore, the retrievals are less sensitive to uncertainties in air temperature than they are to those in wind speed.

3) Effect of Relative Humidity on the Elliptical-New SSM Retrieval Model: As with wind speed and air temperature, relative humidity has a strong diurnal cycle, but with minimum value in the afternoon. Setting relative humidity III as the simulated series that is closest to the measured relative humidity, the relative humidity I and V series are the series with the greatest error in this paper, as shown in Fig. 6. The greater the uncertainty of relative humidity, the larger is the error of the SSM retrievals. As the uncertainty exceeds $20 \%$, the accuracy of the elliptical-new SSM retrieval model is minimized. However, a relative humidity value that is higher than the true value will cause more error than one that is lower than the true value. Thus, the SSM retrievals obtained from relative humidity I are less accurate than those obtained from relative humidity V. From relative humidities I to III, the error of SSM retrieval increases by $0.018 \mathrm{~m}^{3} / \mathrm{m}^{3}$ as shown in Table V. Overall, the retrievals are less sensitive to error

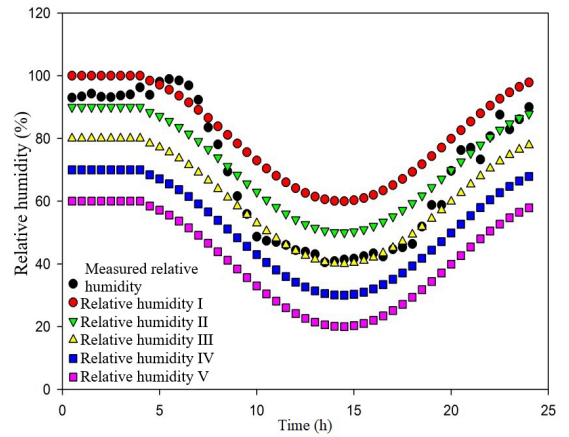

Fig. 6. Measured relative humidity and five sets of simulated relative humidity.

TABLE V

VALIDATION SSM RETRIEVALS With DIFFERENT RELATIVE HuMIDITIES

\begin{tabular}{c|c|c}
\hline Relative humidity & $\mathrm{R}^{2}$ & $\begin{array}{c}\text { RMSE } \\
\left(\mathrm{m}^{3} \mathrm{~m}^{-3}\right)\end{array}$ \\
\hline I & 0.852 & 0.040 \\
II & 0.903 & 0.026 \\
III & 0.920 & 0.022 \\
IV & 0.920 & 0.023 \\
V & 0.911 & 0.026 \\
\hline
\end{tabular}

in relative humidity than to error in air temperature or wind speed.

\section{B. Analysis of Model Sensitivity to LST and NSSR}

To evaluate the impacts of uncertainties in LST and NSSR on SSM retrieval, a sensitivity analysis of LST and NSSR is performed in this paper. Gaussian randomly distributed errors of 1,2 , and $3 \mathrm{~K}$ [error $\operatorname{esT}_{\mathrm{LT}} \sim N\left(0,1^{2}\right)$, error $_{\mathrm{LST}} \sim N\left(0,2^{2}\right)$, and error $\left._{\mathrm{LST}} \sim N\left(0,3^{2}\right)\right]$ are systematically added to the LST. Then, SSM is estimated by using the elliptical-new SSM retrieval model with the noised LST data. Compared with the actual SSM, the root-mean-square error (RMSE) is $0.03 \mathrm{~m}^{3} / \mathrm{m}^{3}$ for error LST $_{2} \sim N\left(0,1^{2}\right), 0.04 \mathrm{~m}^{3} / \mathrm{m}^{3}$ for error $\mathrm{LST} \sim$ $N\left(0,2^{2}\right)$, and $0.06 \mathrm{~m}^{3} / \mathrm{m}^{3}$ for error LST $_{2} \sim N\left(0,3^{2}\right)$. As shown in Fig. 7(a), the correlation coefficient $(R)$ is 0.91 for error $_{\mathrm{LST}} \sim N\left(0,1^{2}\right), 0.81$ for error ${ }_{\mathrm{LST}} \sim N\left(0,2^{2}\right)$, and 0.60 for error LST $_{2} \sim N\left(0,3^{2}\right)$. Similarly, we add Gaussian randomly distributed errors of 10,20 , and $30 \mathrm{~W} / \mathrm{m}^{2}$ to the NSSR [ error $_{\mathrm{NSSR}} \sim N\left(0,10^{2}\right)$, error $_{\mathrm{NSSR}} \sim N\left(0,20^{2}\right)$, and error $\left._{N S S R} \sim N\left(0,30^{2}\right)\right]$. Fig. 7(b) reveals that the RMSE is $0.02 \mathrm{~m}^{3} / \mathrm{m}^{3}$ and that the $R$ value is 0.92 for error ${ }_{\mathrm{NSSR}} \sim$ $N\left(0,10^{2}\right)$. For errorNSSR $\sim N\left(0,20^{2}\right)$, the RMSE is $0.03 \mathrm{~m}^{3} / \mathrm{m}^{3}$ and $R$ is 0.81 . For error $\mathrm{NSSR} \sim N\left(0,30^{2}\right)$, the RMSE is $0.05 \mathrm{~m}^{3} / \mathrm{m}^{3}$ and $R$ is 0.67 . Errors from a Gaussian random distribution are added to the diurnal LST and NSSR for all vegetation conditions and land cover types, and therefore, the results will display the largest possible sensitivity.

\section{Validation and Analysis With In Situ Measurements}

To compare the elliptical-original model and the elliptical-new model and validate their feasibilities, 


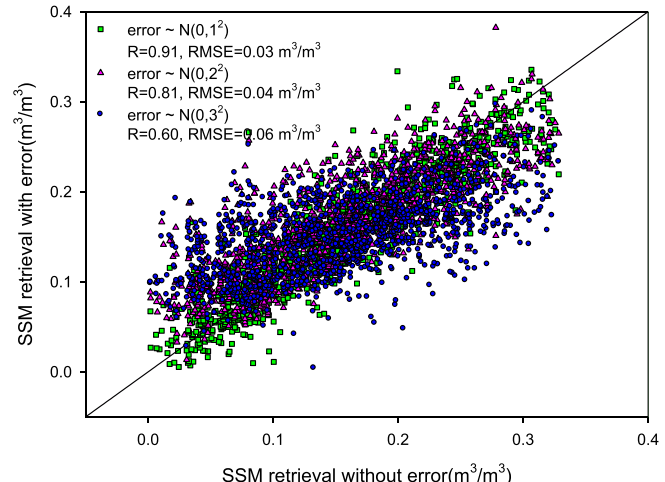

(a)

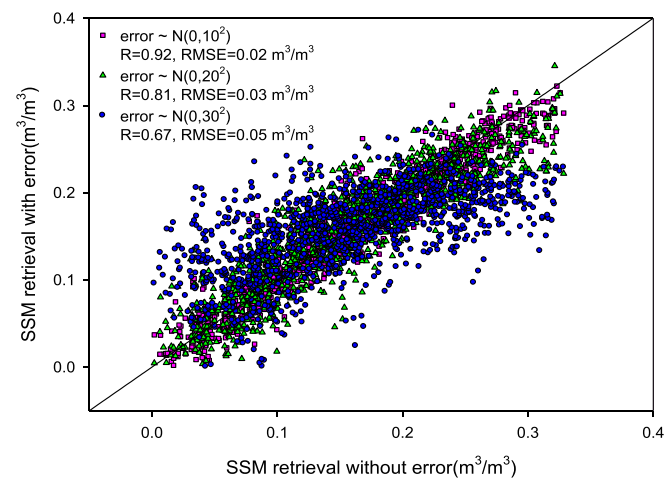

(b)

Fig. 7. Validation of the estimated SSM after adding Gaussian randomly distributed error. (a) Added error to the LST. (b) Added error to the NSSR.

in situ daily-averaged SSM measurements are regarded as references for an evaluation of cloud-free days between July and October in 2010. In this model, SSM is estimated from the elliptical relationship between the diurnal cycle of LST and NSSR. For the elliptical relationship between diurnal LST and NSSR cycles, there should be one diurnal LST-NSSR ellipse for each given location for a cloud-free day. When the weather changes (e.g., clouds occur or last for a while or even rains) during the daytime, LST-NSSR and SSM can also be affected. In this case, the LST-NSSR relationship may not be elliptical, probably leading to the inapplicability of the proposed model. Otherwise, if the LST-NSSR relationship is still ellipse with weather variation, the ellipse model would be applicable. In this case, the model is based on fully cloud-free days to avoid intermittent cloudy or rainy conditions. However, more in depth investigation should be conducted to further explore the effects of clouds or rain events on the estimation of SSM with the proposed model. In addition, under situation of one diurnal LST-NSSR ellipse for each given location for a cloud-free day, the SSM retrieval should be daily averaged. In situ daily-averaged SSM can reflect to some extent the diurnal variation of soil moisture content. Hence, it is feasible to evaluate the model outputted SSM with daily-averaged in situ measurements.

When comparing the SSM retrieval from the ellipticaloriginal model with the in situ measurements, an $R$ value of 0.528 , an RMSE of $0.178 \mathrm{~m}^{3} / \mathrm{m}^{3}$, and a bias of $0.031 \mathrm{~m}^{3} / \mathrm{m}^{3}$ are obtained. The elliptical-new model possesses better

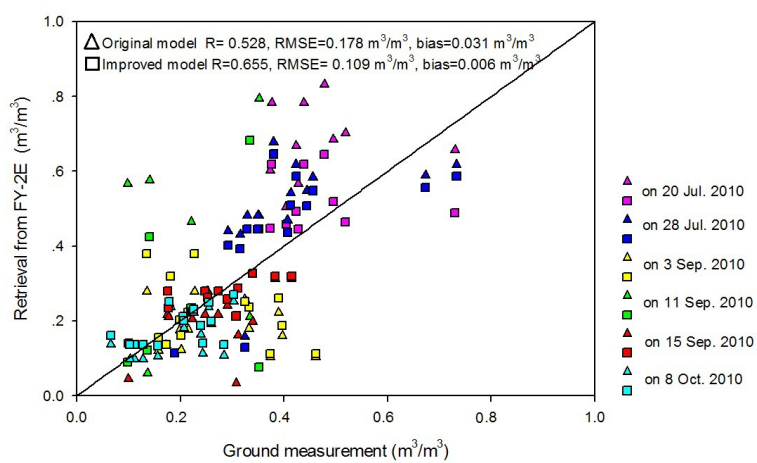

Fig. 8. Validation data for the elliptical-original (triangle) and elliptical-new (rectangle) models with in situ measurements.

TABLE VI

Retrieval Results and Ground Measurement at NST_15

\begin{tabular}{|c|c|c|c|c|c|c|}
\hline \multirow[b]{2}{*}{ Date } & \multicolumn{3}{|c|}{ LST at 11 a.m. (K) } & \multicolumn{3}{|c|}{ Daily average $\operatorname{SSM}\left(\mathrm{m}^{3} / \mathrm{m}^{3}\right)$} \\
\hline & $\begin{array}{l}\text { Retrie } \\
\text { val }\end{array}$ & $\begin{array}{l}\text { Ground } \\
\text { measure } \\
\text { ment }\end{array}$ & BIAS* & $\begin{array}{l}\text { Retri } \\
\text { eval }\end{array}$ & $\begin{array}{l}\text { Ground } \\
\text { measure } \\
\text { ment }\end{array}$ & BIAS* \\
\hline $\begin{array}{l}20 \\
\text { Jul. }\end{array}$ & $\begin{array}{l}293.1 \\
4\end{array}$ & 286.25 & 6.89 & 0.657 & 0.730 & -0.073 \\
\hline $\begin{array}{l}28 \\
\text { Jul. }\end{array}$ & $\begin{array}{l}299.4 \\
9\end{array}$ & 289.45 & 10.04 & 0.557 & 0.673 & -0.116 \\
\hline 3 Sep. & $\begin{array}{l}295.8 \\
3\end{array}$ & 281.85 & 13.98 & 0.241 & 0.507 & -0.266 \\
\hline $\begin{array}{l}15 \\
\text { Sep. }\end{array}$ & $\begin{array}{l}297.0 \\
1\end{array}$ & 283.55 & 13.46 & 0.202 & 0.503 & -0.301 \\
\hline
\end{tabular}

accuracy, with an $R$ value of 0.655 , an RMSE of $0.109 \mathrm{~m}^{3} / \mathrm{m}^{3}$, and a bias of $0.006\left(\mathrm{~m}^{3} / \mathrm{m}^{3}\right)$. The results in Fig. 8 reveal a good correlation between the retrieved and ground measurements. The satellite SSM retrievals in July are higher than the ground measurements, potentially due to atmospheric data affecting the model when SSM is high. The atmospheric forcing data, including wind speed, used to drive the CoLM might affect the model coefficients causing the SSM retrievals to be higher than the ground measurements.

1) Analysis of the Error: Station NST_04 is situated in marshland. Station NST_13 is located in high vegetationcover conditions. The FVC at NST_13 can sometimes exceed $70 \%$, which is too high to obtain an accurate SSM retrieval result [51].

Station NST_15 is situated along a hill slope with a large elevation difference. Heterogeneous surfaces might cause errors in the estimation of LST and NSSR. The elliptical SSM retrieval model is based on the synergistic use of diurnal cycles of LST and NSSR, and thus, errors in the LST and NSSR estimates will influence the SSM estimation. Table VI reveals that the SSM estimation will contain larger error as the LST estimate becomes less accurate. For example, the SSM estimate is more accurate on 20 July than on any other day because of the high accuracy of the LST retrieval on this day. Furthermore, if the LST retrieval is higher than the true value, the smaller ellipse rotation angle will reduce the SSM retrieval value relative to the in situ measurement, as is evidenced 


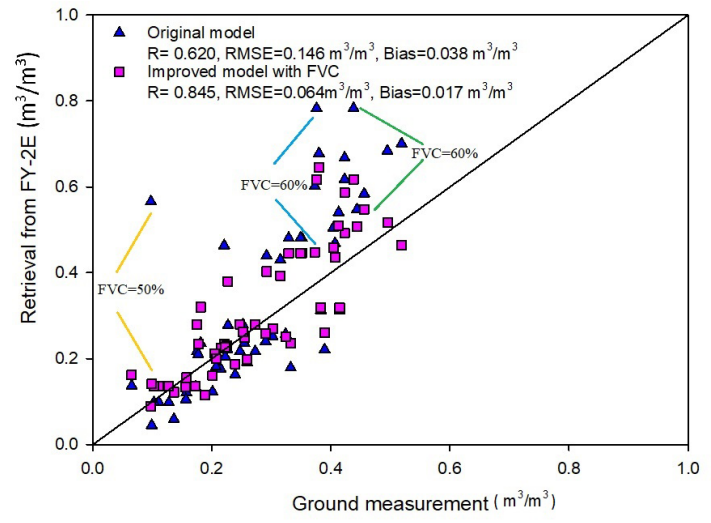

Fig. 9. Validation using the in situ measurements.

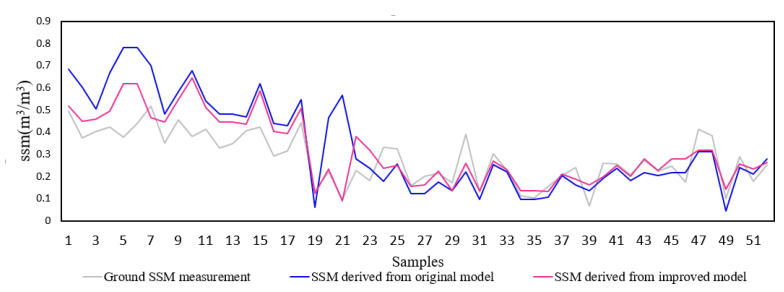

Fig. 10. SSM trends in comparison with in situ measurements.

in Table VI. Thus, the ellipse-new model is not suitable for station NST_15.

Due to the high uncertainties from LST, the ellipse-new model is not suitable for stations NST_04, NST_13, and NST_15. Therefore, a subset of ground-based stations will be used for validation.

2) Validation With Subset of Ground-Based Stations: Excluding the stations NST_04, NST_13, and NST_15, the in situ measurements are used for the validation process. As shown in Fig. 9, the results are much more effective when considering FVC, as evidenced by an $R$ of 0.845 , an RMSE of $0.064 \mathrm{~m}^{3} / \mathrm{m}^{3}$, and a bias of $0.017 \mathrm{~m}^{3} / \mathrm{m}^{3}$. These results demonstrate that using the elliptical-original model to derive the SSM with the same set of coefficients for bare soil will enlarge the error and generate an $R$ of 0.620 , an RMSE of $0.146 \mathrm{~m}^{3} / \mathrm{m}^{3}$, and a bias of $0.038 \mathrm{~m}^{3} / \mathrm{m}^{3}$. From Fig. 9 , it can be seen that the discrepancies between original model and in situ measurements get smaller when the FVC is accounted in the new retrieval model. In particular, we label the samples that has large bias with original model, while has better agreement with in situ measurements when the FVC is accounted in the new retrieval model. To further compare the elliptical-original and elliptical-new models, the SSM trends and the field-scaled SSM measurements are shown in Fig. 10. Regardless of whether SSM is derived from the original- or elliptical-new model, it exhibits the same trend as the ground SSM measurements. In addition, it is evident that the SSM retrievals using the elliptical-new model (red line) are much more similar to the field-scaled SSM measurements (blue line) than are the retrievals based on the original model. Therefore, to precisely derive SSM, different vegetation conditions must be considered to optimize the applicability of the model at temporal and spatial scales.

\section{Summary AND CONCLUSION}

SSM, which plays important roles in agricultural applications, environmental and climate systems, and weather forecasting and carbon/nitrogen cycling, is a key land surface variable in the earth system. Due to the capability of geostationary satellites to acquire observations more frequently relative to polar orbiting satellites, methods of greater practicality and precision can be developed. In this paper, we generate an improved and novel SSM retrieval model based on the synergistic use of diurnal cycles of LST and NSSR. Previous investigations have demonstrated the feasibility of the elliptical-original SSM retrieval model for bare soils in sparsely vegetated areas where the FVC varies from 0 to 0.7 . However, the coefficients of the elliptical-original model are incapable of distinguishing different vegetation conditions. In this paper, the elliptical-new model is optimized by accounting for the influences of different FVC values. First, the diurnal cycles of LST, which are estimated using the generalized splitwindow algorithm [43]-[45], and of NSSR [46] are calculated. Second, FVC is calculated based on a dimidiate pixel model and a MODIS NDVI product to optimize the model for the estimation of SSM at the regional scale. Subsequently, SSM retrieval is estimated using the elliptical-new model while considering the impacts of different FVC values. Finally, a preliminary validation is conducted by employing in situ ground measurements for the counties of Maqu, Luqu, and Ruoergai, which are located to the east of the SAYR. When comparing the original- and elliptical-new model, stronger relationship between the ground measurements and the FY-2E-derived SSM using the elliptical-new model is reported, with an $R$ of 0.845 , an RMSE of $0.064 \mathrm{~m}^{3} / \mathrm{m}^{3}$, and a bias of $0.017 \mathrm{~m}^{3} / \mathrm{m}^{3}$. The SSM retrieval results using the ellipticalnew model are more similar to the field-scaled SSM measurements than are those obtained using the original model. The FY-2E-derived SSM based on the elliptical-new model exhibits less error than does the SSM estimated from the ellipticaloriginal model. Therefore, the preliminary validation using in situ measurements confirms that it is necessary to consider the impacts of FVC for improved SSM retrieval.

The sensitivity of the model to atmospheric forcing is investigated. The retrievals have larger biases when the wind speed, air temperature, or humidity has large uncertainties. The ellipse model is most sensitive to wind speed, which indicates a requirement for high-accuracy wind speed measurements to estimate soil moisture with the proposed model.

In the future studies, we will obtain LST and NSSR by employing high-quality geostationary satellite data. Furthermore, due to the observation of several errors observed during FVC estimation, including errors in the determination of the angle and some bidirectional reflectance distribution function effects from $\pm 55^{\circ}$ of the MODIS threshold, the accuracy of FVC retrieval will be improved and validated. Along with a point-scale validation, cross-comparisons with other existing SSM products will be conducted in the future studies. 


\section{ACKNOWLEDGMENT}

The authors would like to thank the Faculty of GeoInformation Science and Earth Observation, University of Twente (ITC), Enschede, The Netherlands, Chinese Academy of Science-Cold and Arid Regions Environmental and Engineering Research Institute (CAS-CAREERI), Lanzhou, China, International Soil Moisture Network, Vienna, Austria, and National Satellite Meteorological Center China Meteorological Administration (NSMC), Beijing, China, for providing the soil moisture measurements data, meteorological data, and FY-2E data.

\section{REFERENCES}

[1] M. H. Cosh, T. J. Jackson, R. Bindlish, and J. H. Prueger, "Watershed scale temporal and spatial stability of soil moisture and its role in validating satellite estimates," Remote Sens. Environ., vol. 92, no. 4, pp. 427-435, 2004.

[2] W. A. Dorigo et al., "Evaluation of the ESA CCI soil moisture product using ground-based observations," Remote Sens. Environ., vol. 162, pp. 380-395, Jun. 2015.

[3] D. R. Legates et al., "Soil moisture: A central and unifying theme in physical geography," Prog. Phys. Geogr., vol. 35, no. 1, pp. 65-86, 2011.

[4] J. Peng, A. Loew, O. Merlin, and N. E. C. Verhoest, "A review of spatial downscaling of satellite remotely sensed soil moisture," Rev. Geophys., vol. 55, no. 2, pp. 341-366, 2017.

[5] Z.-L. Li et al., "A review of current methodologies for regional evapotranspiration estimation from remotely sensed data," Sensors, vol. 9 , no. 5, pp. 3801-3853, 2009.

[6] R. Zhang, J. Tian, H. Su, X. Sun, S. Chen, and J. Xia, "Two improvements of an operational two-layer model for terrestrial surface heat flux retrieval," Sensors, vol. 8, no. 10, pp. 6165-6187, 2008.

[7] L. He, J. M. Chen, J. Liu, S. Bélair, and X. Luo, "Assessment of SMAP soil moisture for global simulation of gross primary production," J. Geophys. Res. Biogeosci., vol. 122, no. 7, pp. 1549-1563, 2017.

[8] W. B. Anderson et al., "Towards an integrated soil moisture drought monitor for East Africa," Hydrol. Earth Syst. Sci., vol. 16, pp. 2893-2913, Aug. 2012.

[9] E. Meyles, A. Williams, L. Ternan, and J. Dowd, "Runoff generation in relation to soil moisture patterns in a small Dartmoor catchment, Southwest England," Hydrol. Process., vol. 17, no. 2, pp. 251-264, 2003.

[10] J. Peng, A. Loew, S. Zhang, J. Wang, and J. Niesel, "Spatial downscaling of satellite soil moisture data using a vegetation temperature condition index," IEEE Trans. Geosci. Remote Sens., vol. 54, no. 1, pp. 558-566, Jan. 2016.

[11] G. P. Petropoulos, G. Ireland, and B. Barrett, "Surface soil moisture retrievals from remote sensing: Current status, products \& future trends," Phys. Chem. Earth, A/B/C, vols. 83-84, pp. 36-56, Mar. 2015.

[12] N. Sánchez, J. Martínez-Fernández, and A. González-Zamora, "A combined approach with SMOS and modis to monitor agricultural drought," Int. Arch. Photogramm. Remote Sens. Spatial Inf. Sci., vol. XLI-B8, pp. 393-398, Jul. 2016

[13] L. Brocca, F. Melone, T. Moramarco, and R. Morbidelli, "Spatialtemporal variability of soil moisture and its estimation across scales," Water Resour. Res., vol. 46, no. 2, p. W02516, 2010.

[14] J. Peng, J. Niesel, A. Loew, S. Zhang, and J. Wang, "Evaluation of satellite and reanalysis soil moisture products over Southwest China using ground-based measurements," Remote Sens., vol. 7, no. 11, pp. 15729-15747, 2015.

[15] J. Peng and A. Loew, "Recent advances in soil moisture estimation from remote sensing," Water, vol. 9, no. 7, p. 530, 2017.

[16] T. Jagdhuber, I. Hajnsek, A. Bronstert, and K. P. Papathanassiou, "Soil moisture estimation under low vegetation cover using a multi-angular polarimetric decomposition," IEEE Trans. Geosci. Remote Sens., vol. 51, no. 4, pp. 2201-2215, Apr. 2013.

[17] T. Jagdhuber, I. Hajnsek, and K. P. Papathanassiou, "An iterative generalized hybrid decomposition for soil moisture retrieval under vegetation cover using fully polarimetric SAR," IEEE J. Sel. Topics Appl. Earth Observ. Remote Sens., vol. 8, no. 8, pp. 3911-3922, Aug. 2015.

[18] F. Mattia, G. Satalino, V. R. N. Pauwels, and A. Loew, "Soil moisture retrieval through a merging of multi-temporal L-band SAR data and hydrologic modelling," Hydrol. Earth Syst. Sci., vol. 13, no. 3, pp. 343-356, 2009
[19] P. Leng, Z.-L. Li, S.-B. Duan, M.-F. Gao, and H.-Y. Huo, "A practical approach for deriving all-weather soil moisture content using combined satellite and meteorological data," ISPRS J. Photogramm. Remote Sens., vol. 131, pp. 40-51, Sep. 2017.

[20] W. Zhao, A. Li, and T. Zhao, "Potential of estimating surface soil moisture with the triangle-based empirical relationship model," IEEE Trans. Geosci. Remote Sens., vol. 55, no. 11, pp. 6494-6504, Nov. 2017.

[21] L. He, J. M. Chen, and K. S. Chen, "Simulation and SMAP observation of sun-glint over the land surface at the L-band," IEEE Trans. Geosci. Remote Sens., vol. 55, no. 5, pp. 2589-2604, May 2017.

[22] L. Brocca et al., "Soil moisture estimation through ASCAT and AMSR E sensors: An intercomparison and validation study across Europe," Remote Sens. Environ., vol. 115, no. 12, pp. 3390-3408, 2011.

[23] A. Loew and F. Schlenz, "A dynamic approach for evaluating coarse scale satellite soil moisture products," Hydrol. Earth Syst. Sci., vol. 15, pp. 75-90, Jan. 2011.

[24] C.-H. Su, D. Ryu, R. I. Young, A. W. Western, and W. Wagner, "Inter-comparison of microwave satellite soil moisture retrievals over the Murrumbidgee Basin, southeast Australia," Remote Sens. Environ., vol. 134, pp. 1-11, Jul. 2013.

[25] N. Wanders et al., "Observation uncertainty of satellite soil moisture products determined with physically-based modeling," Remote Sens. Environ., vol. 127, pp. 341-356, Dec. 2012.

[26] W. Zhao and A. Li, "A comparison study on empirical microwave soil moisture downscaling methods based on the integration of microwaveoptical/IR data on the Tibetan Plateau," Int. J. Remote Sens., vol. 36, nos. 19-20, pp. 4986-5002, 2015.

[27] D. Entekhabi et al., "The soil moisture active passive (SMAP) mission," Proc. IEEE, vol. 98, no. 5, pp. 704-716, May 2010.

[28] A. Colliander et al., "Validation and scaling of soil moisture in a semiarid environment: SMAP validation experiment 2015 (SMAPVEX15)," Remote Sens. Environ., vol. 196, pp. 101-112, Jul. 2017.

[29] D. Zhang and G. Zhou, "Estimation of soil moisture from optical and thermal remote sensing: A review," Sensors, vol. 16, no. 8, p. 1308, 2016.

[30] D. Zhang, R. Tang, B.-H. Tang, H. Wu, and Z.-L. Li, "A simple method for soil moisture determination from LST-VI feature space using nonlinear interpolation based on thermal infrared remotely sensed data," IEEE J. Sel. Topics Appl. Earth Observ. Remote Sens., vol. 8, no. 2 , pp. 638-648, Feb. 2015.

[31] D. Zhang et al., "Validation of a practical normalized soil moisture model with in situ measurements in humid and semi-arid regions," Int. J. Remote Sens., vol. 36, nos. 19-20, pp. 5015-5030, 2015.

[32] P. Leng, X. Song, S.-B. Duan, and Z.-L. Li, "A practical algorithm for estimating surface soil moisture using combined optical and thermal infrared data," Int. J. Appl. Earth Observ. Geoinf., vol. 52, pp. 338-348, Oct. 2016.

[33] P. Leng, X. Song, Z.-L. Li, J. Ma, F. Zhou, and S. Li, "Bare surface soil moisture retrieval from the synergistic use of optical and thermal infrared data," Int. J. Remote Sens., vol. 35, no. 3, pp. 988-1003, 2014

[34] P. J. Wetzel, D. Atlas, and R. H. Woodward, "Determining soil moisture from geosynchronous satellite infrared data: A feasibility study," J. Climate Appl. Meteorol., vol. 23, no. 3, pp. 375-391, 1984.

[35] W. Zhao et al., "Determination of bare surface soil moisture from combined temporal evolution of land surface temperature and net surface shortwave radiation," Hydrol. Process., vol. 27, no. 19, pp. 2825-2833, 2013

[36] P. Leng, X. Song, S.-B. Duan, and Z.-L. Li, "Generation of continuous surface soil moisture dataset using combined optical and thermal infrared images," Hydrol. Process., vol. 31, no. 6, pp. 1398-1407, 2017.

[37] H. Tian et al., "Evidence for a recent warming and wetting in the source area of the Yellow River (SAYR) and its hydrological impacts," J. Geogr. Sci., vol. 25, no. 6, pp. 643-668, 2015.

[38] Y. Wang, X. Song, P. Leng, C. Sun, and X. Liu, "Estimation of surface soil moisture using FengYun-2E (FY-2E) data: A case study over the source area of the Yellow River," in Proc. IEEE Int. Geosci. Remote Sens. Symp. (IGARSS), Jul. 2016, pp. 4327-4330.

[39] D. Ji and Y. Dai, "The common land model (CoLM) technical guide," College Global Change Earth Syst. Sci., Beijing Normal Univ., Beijing, China, Tech. Rep., 2010. [Online]. Available: http://globalchange. bnu.edu.cn/download/doc/CoLM/CoLM_Technical_Guide.pdf

[40] S. Luo, S. Lü, and Y. Zhang, "Development and validation of the frozen soil parameterization scheme in Common Land Model," Cold Regions Sci. Technol., vol. 55, no. 1, pp. 130-140, 2009.

[41] Y.-M. Song, W.-D. Guo, and Y.-C. Zhang, "Simulation of latent heat flux exchange between land surface and atmosphere in temperate mixed forest and subtropical artificial coniferous forest sites in China by CoLM," Plateau Meteorol., vol. 8, no. 5, pp. E60429-E60433, 2008. 
[42] G.-M. Jiang, Z.-L. Li, and F. Nerry, "Land surface emissivity retrieval from combined mid-infrared and thermal infrared data of MSGSEVIRI," Remote Sens. Environ., vol. 105, no. 4, pp. 326-340, 2006.

[43] B.-H. Tang et al., "Generalized split-window algorithm for estimate of land surface temperature from Chinese geostationary FengYun meteorological satellite (FY-2C) Data," Sensors, vol. 8, pp. 933-951, Sep. 2008.

[44] X. Song et al., "Estimation of land surface temperature using FengYun$2 \mathrm{E}$ (FY-2E) data: A case study of the source area of the Yellow River," IEEE J. Sel. Topics Appl. Earth Observ. Remote Sens., vol. 10, no. 8, pp. 3744-3751, Aug. 2017.

[45] Z. Wan and J. Dozier, "A generalized split-window algorithm for retrieving land-surface temperature from space," IEEE Trans. Geosci. Remote Sens., vol. 34, no. 4, pp. 892-905, Jul. 1996.

[46] Y. Wang, X. Song, and R. Wang, "Estimation of net surface shortwave radiation using FengYun-2E (FY-2E) data on cloud-free days," J. Univ. Chin. Acad. Sci., vol. 33, no. 6, pp. 769-774, 2016.

[47] R. Liu, "Evapotranspiration estimated by using Geostationary Meteorological Satellite data over the source water region of the Yellow River," Ph.D. dissertation, Cold Arid Regions Environ. Eng. Res. Inst., Univ. Chinese Acad. Sci., Gansu, China, 2011.

[48] Z.-L. Li, L. Jia, Z. Su, Z. Wan, and R. Zhang, "A new approach for retrieving precipitable water from ATSR2 split-window channel data over land area," Int. J. Remote Sens., vol. 24, no. 24, pp. 5095-5117, 2003.

[49] Y. Ding et al., "Quantifying the impact of NDVIsoil determination methods and NDVIsoil variability on the estimation of fractional vegetation cover in Northeast China," Remote Sens., vol. 8, no. 1, p. 29, 2016.

[50] G. Gutman and A. Ignatov, "The derivation of the green vegetation fraction from NOAA/AVHRR data for use in numerical weather prediction models," Int. J. Remote Sens., vol. 19, no. 8, pp. 1533-1543, 1998.

[51] P. Leng, X. Song, Z. L. Li, Y. Wang, and D. Wang, "Effects of vegetation and soil texture on surface soil moisture retrieval using multi-temporal optical and thermal infrared observations," Int. J. Remote Sens., vol. 36 , nos. 19-20, pp. 4972-4985, 2015.

[52] G. B. Bonan, "A land surface model (LSM version 1.0) for ecological, hydrological, and atmospheric studies: Technical description and user's guide," Nat. Center Atmospheric Res., Boulder, CO, USA, Tech. Rep. NCAR/TN-417+STR, 1996.

[53] A. M. Hasson, N. I. Al-Hamadani, and A. A. Al-Karaghouli, "Comparison between measured and calculated diurnal variations of wind speeds in northeast Baghdad," Solar Wind Technol., vol. 7, no. 4, pp. 481-487, 1990.

[54] A. Dai and C. Deser, "Diurnal and semidiurnal variations in global surface wind and divergence fields," J. Geophys. Res. Atmos., vol. 104, no. D24, pp. 31109-31125, 1999.

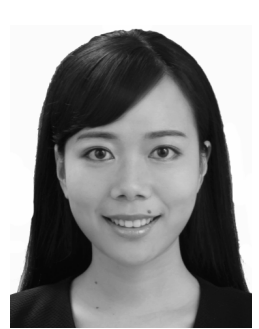

Yawei Wang received the B.S. degree in geographic information system from Sichuan Normal University, Chengdu, China, in 2013, and the M.S. degree in geographic information system from University of Chinese Academy of Sciences, Beijing, China, in 2016. She is currently pursuing the Ph.D. degree from the Ludwig Maximilian University of Munich, Munich, Germany.

Her research interests include moisture and energy fluxes from remote sensing data.

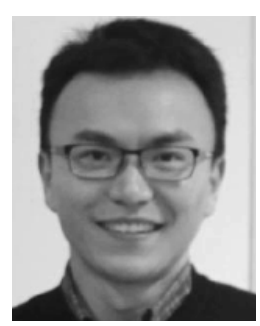

Jian Peng (M'12) received the Ph.D. degree in earth science from the Max Planck Institute for Meteorology (MPI-M), Hamburg, Germany.

He was a Research Scientist at the University of Munich, Munich, Germany, and a Post-Doctoral Researcher at MPI-M. He is currently a Senior Researcher with the School of Geography and the Environment, University of Oxford, Oxford, U.K. His research interests include the quantitative retrieval of land surface parameters from remote sensing data, understanding land-atmosphere interactions using earth system models and observational data, development of downscaling schemes, quantification of climate change impact on water resources, estimation of high-resolution land surface water and energy fluxes from satellite observations, and the investigation of hydrological and climatic extremes and their impacts on vegetation.

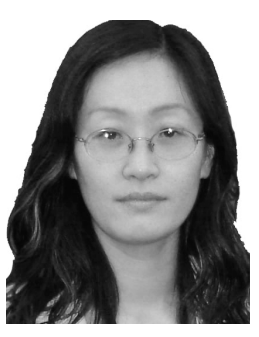

Xiaoning Song (M'04) received the Ph.D. degree in geographic information system from the Institute of Remote Sensing Applications, Chinese Academy of Sciences, Beijing, China, in 2004.

She is currently a Professor with the University of Chinese Academy of Sciences, Beijing. Her research interests include parameters inversion of land surface temperature, surface emissivity, surface albedo, leaf area index, net primary production, evapotranspiration, and soil moisture.

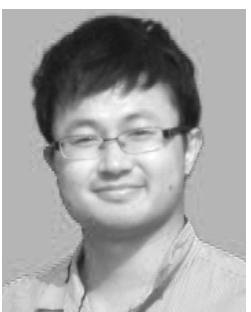

Pei Leng received the Ph.D. degree in geographic information system from the University of Chinese Academy of Sciences, Beijing, China, in 2015.

$\mathrm{He}$ is currently with the Key Laboratory of Agri-Informatics, Ministry of Agriculture/Institute of Agricultural Resources and Regional Planning, Chinese Academy of Agricultural Sciences, Beijing. His research interests include the moisture and energy fluxes from remote sensing data.

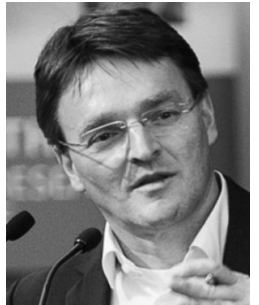

Ralf Ludwig received the Diploma and Ph.D. degrees in physical geography, remote sensing geology and geophysics from the Geography Department, Ludwig Maximilian University of Munich (LMU), Munich, Germany, in 1993 and 1999, respectively.

He is the Dean of the Faculty of Geosciences and a Professor of applied physical geography and environmental modeling with Department of Geography, LMU. His research interests include process-based and spatially distributed hydrological modeling at the catchment scale, data assimilation and model integration for water resources, land use and climate change impact assessment from Mediterranean to subarctic environments, and the energy-environment interface.

Dr. Ludwig is a Steering Committee Member of the Helmholtz Research School MICMoR and the Spokesperson of the Albertan-Bavarian EnergyEnvironment Research Network ABBY-Net. He is the member of the European Geosciences Union, the German Society for Photogrammetry, Remote Sensing and Geoinformation, and the German Society for Canadian Studies.

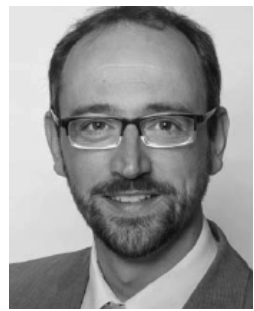

Alexander Loew (M'04) received the M.S. degree in geography and the Ph.D. degree in physical geography from the Ludwig Maximilian University of Munich (LMU), Munich, Germany, in 2001 and 2004, respectively.

$\mathrm{He}$ is currently a Full Professor of physical geography and microwave remote sensing with the LMU His research interests include the derivation of quantitative land surface parameters from remote sensing data, the assimilation of remote sensing data into climate and land surface process models, and the evaluation of climate models using observational data 